\title{
Hedonic valuation of flood
}

\author{
M. J. Choi \& J. W. Lee \\ Graduate School of Green Growth, KAIST College of Business, Korea
}

\begin{abstract}
This study investigates the amenity value of flood dividing flood into two aspects. One aspect is the physical amount of rainfall consisting of annual rainfall and rainfall intensity that are expected to increase due to climate change. The other aspect is infrastructure for flood protection: Percentage of impermeable surface ratio and sewer dredging ratio. Infrastructure for flood protection assists cities especially those which are rapidly urbanized to reduce flood risks and to develop adaptation capacity for climate change such as increased rainfall. With increasing concerns for climate change, there are studies with an economic point of view that investigate the marginal willingness to pay for climate variables from. In this study, we hand collect 2,500 real estate transactions in Seoul for the year 2014 to assess the amenity value of flood using the hedonic property value technique. Our findings indicate that rainfall and infrastructure for flood protection significantly affect housing prices. Some policy implications are provided.

Keywords: climate change, rainfall, flood, hedonic pricing model.
\end{abstract}

\section{Introduction}

In the last few decades, rapid urbanization has intensified with economic development and population growth prompting more than half the global population to live in urbanized cities. At the same time, severe social problems have emerged in urbanized cities along with physical and economic expansion. Among these social problems, the risks of climate change induced by lack of infrastructure for climate change adaptation have increased. The Intergovernmental Panel on Climate Change (IPCC) [1] examined the connections between urbanization and climate change in relation to patterns and conditions of climate risk, impact, and vulnerability in the fifth assessment report. According to this report, a growing proportion of the world's population will be exposed to the 
direct impacts of climate change in urban areas. Especially, in urbanized cities, flood risks have increased with growing areas with impermeable land surfaces and the decreased capability of rainfall retention.

Seoul, the capital of South Korea, has been urbanized since late 1960s with rapid population growth and improving socio-economic structure. During this process, Seoul had the highest impermeable surface ratio among all cities in South Korea. In 2013, Seoul's average impermeable surface ratio was approximately $57 \%$, much higher than the $6 \%$ level of the nation. The seasonal rain front crossing South Korea induces frequent flooding concentrated in summer season, and the lack of permeable surface aggravates flood risks of the city.

In this context, infrastructures such as green roofs, green walls and permeable pavements are required to facilitate the city for increasing its water retention capacity and for reducing flood risks. This infrastructure is considered to be a green infrastructure. According to Ahern [2], Green infrastructure is defined as 'spatially and functionally integrated systems and networks of protected landscapes supported with artificial and hybrid infrastructure that provide multiple complementary ecosystem and functions to the public'.

In the case of the city of Seoul, efforts to diminish flood risks have been developed with administrative, executive and legal support such as the Sewerage Act and the sewerage management system. These efforts aided in reducing flood risks arising from overcapacity of sewer pipes.

The level of impermeable area and sewer pipes have a complex relationship. The imbalance between the two may cause flood of roads and properties. Wheater [9] developed new technology for examining the interaction between sewer flows and surface flooding for intra-urban flood risk assessment for the design and management of urban infrastructures.

\section{Hedonic pricing model}

\subsection{Hedonic function}

The theoretical framework of hedonic pricing model was developed by Rosen [8]. According to his study, hedonic prices are defined as the implicit prices of attributes and are revealed to economic agents from observed prices of differentiated products and the specific amounts of characteristics associated with them. Implicit prices of attributes are examined by the econometric regression analysis.

Under a hedonic pricing model, Can [3] explained housing prices, $\mathrm{P}(\mathrm{H})$, and the level of characteristics contained in vector $\mathrm{H}$ have a functional relationship, given that housing is a heterogeneous commodity differentiated into a bundle of attributes, $\mathrm{H}=\left(h_{1}, h_{2}, \ldots, h_{k}\right)$. The hedonic function for market prices of the housing can be represented as follow.

$$
\mathbf{P}(\mathbf{H})=\mathbf{f}\left(\boldsymbol{h}_{1}, \boldsymbol{h}_{2}, \ldots, \boldsymbol{h}_{\boldsymbol{k}}\right)
$$


Locational characteristics (e.g. access to economic and social facilities), structural characteristics (e.g. size, number of rooms, floor) and neighbourhood characteristics (e.g. congestion, noise and air pollution levels) are examples of housing attributes composing hedonic function, eqn (1).

There are a few functional forms of hedonic pricing model. The dominantly used functional forms are (1) linear function in which dependent variable (housing prices) and independent variables (housing attributes) are shown as their own values, (2) semi-log function in which dependent variable is represented as logarithmic value only, and (3) double-log function in which all of the continuous variables are converted into logarithms.

\subsection{Applications in rainfall}

Hedonic pricing model is utilized to indirectly assess the value of environmental amenities reflected in housing markets when there is no obvious markets for environmental amenities. With development of hedonic pricing model, several studies using hedonic pricing model for environmental amenities such as air quality, noise, noxious power generating plants and toxic materials have been conducted.

There were few studies investigating the relationship between the value of rainfall and housing prices. Englin [4] found both annual and seasonal rainfall patterns in Olympic Peninsula in Washington State, US, affect the overall valuation of rainfall as a climatological resource by conducting econometric analysis for long-term average annual rainfall and the variation in rainfall within the year. Rehdanz [7] discovered that British people would prefer a greater distribution of precipitation across the seasons by investigating the amenity value of climate such as average hours of sunshine, average wind speed, average precipitation and average temperature.

In studies of South Korea's case, explanatory variables related to environment, such as green space, air pollution, noise and scenic right, have been examined recently. But hedonic pricing studies for identifying the implicit prices of climate change are not being worked out.

\section{Data}

\subsection{Hypothesis}

In this study, there is a hypothesis formulated, which is that characteristics of rainfall and infrastructure for flood protection affect housing prices. If these are identified as statistically significant on housing pricing model, it can be concluded that the hypothesis is true. Furthermore, through the estimated coefficient, we can see the impact of each characteristic on housing prices.

\subsection{Study area and samples}

Seoul was selected for this analysis. Seoul, the capital of South Korea, has 25 subboroughs. Seoul is divided into north and south area by the Han River flowing 
through Seoul from east to west. Seoul has a humid continental climate featuring hot summer, dry winter and extreme seasonality. Influenced by the North Pacific high-pressure system, Seoul has hot and humid weather in summer. On the contrary, the city has cold and dry weather in winter caused by the influence of Siberian high-pressure system. Seoul's annual average temperature during 19812010 is around $12.5^{\circ} \mathrm{C}\left(54.5^{\circ} \mathrm{F}\right)$ with large annual range of temperature. During 1981-2010, the amount of rainfall of Seoul in summer (June, July, and August) is $892.1 \mathrm{~mm}$, which is almost $61 \%$ of total annual rainfall while the amount of rainfall in winter (December, January, and February) accounts for only 5\% of total annual rainfall.

\subsection{Variables}

Information on real transaction prices on apartments in 2014 in Seoul was obtained from Ministry of Land, Infrastructure and Transport (MoLIT). Among various types of housing, apartments are selected as the subject of this study, with advantage of having standardized and readily available information such as area, floor, and heating system. Also, Seoul had the highest ratio of apartments with $42.6 \%$ in 2014 , followed by detached houses with $36.5 \%$, multi-family houses with $11.3 \%$, and row houses with $4.4 \%$. Among 76,000 data excluding redeveloped apartments, 2,500 data which were composed of 100 data from each borough were randomly selected in order to avoid local bias. Redeveloped apartments which have a premium with an enhancement in living conditions were excluded.

As the independent variables, flood-related variables are divided into two aspects. One is the physical characteristic of rainfall which consists of annual rainfall and rainfall intensity. These borough-scale data were obtained from Automatic Weather Stations (AWS) operated by the Korea Meteorological Administration (KMA). As Englin [4] pointed out, snow and rainfall which are aggregated into precipitation may have different economic valuations. In this context, rainfall from May to October in which average monthly temperature is above $15^{\circ} \mathrm{C}$ was considered in this study in order to distinguish between snow and rainfall clearly. Rainfall intensity which is the amount of rainfall per rainy days was calculated based on rainfall from May to October. The physical characteristics of rainfall are represented as the average amount during 2010-2013 from the point of view that pattern of rainfall over the years affect choice of housing attributes such as location and type. The other aspect of flood variables is related to infrastructure for flood protection: impermeable surface ratio and sewer dredging ratio. The extent of flood damage varies according to the level of infrastructure reflecting sewage treatment capacity. These variables in 2013 were obtained from Seoul Metropolitan Government.

The other independent variables composing of the structural characteristics and locational characteristics of housing, which were proved to affect prices on apartments significantly from many studies, were chosen for the study. Real transaction prices per exclusive use area is regarded as the dependent variable in order to normalize real transaction prices of apartments with different area. All selected variables with description is shown in Table 1. 
Table 1: Description of variables.

\begin{tabular}{|c|c|}
\hline Variables & Description \\
\hline \multicolumn{2}{|l|}{ Dependent } \\
\hline Price & $\begin{array}{l}\text { Real transaction prices (ten thousand won) per } \\
\text { exclusive use area (square meter) }\end{array}$ \\
\hline \multicolumn{2}{|l|}{ Independent } \\
\hline \multicolumn{2}{|l|}{ Structural } \\
\hline Floor & Living floor of each household \\
\hline Age & Building age of each apartment \\
\hline Floor ratio & Floor are ratio $(\%)$ of each apartment \\
\hline Building ratio & Building-to-land ratio (\%) of each apartment \\
\hline Building & $\begin{array}{l}\text { The number of buildings in each apartment } \\
\text { complex }\end{array}$ \\
\hline Parking & The number of parking lots per each household \\
\hline Heating(Dummy) & $\begin{array}{l}\text { Heating method } \\
(\text { District heating }=1, \text { Otherwise }=0)\end{array}$ \\
\hline Brand(Dummy) & $\begin{array}{l}\text { Apartment's brand preference } \\
(\text { Top } 5 \text { brands }=1 \text {, Otherwise }=0 \text { ) }\end{array}$ \\
\hline \multicolumn{2}{|l|}{ Locational } \\
\hline Gangnam(Dummy) & $\begin{array}{l}\text { Most expensive area } \\
(\text { Gangnam, Seocho, and Songpa borough }=1 \text {, } \\
\text { Otherwise }=0)\end{array}$ \\
\hline Fiscal & Self-reliance ratio (\%) of each borough in 2013 \\
\hline $\begin{array}{l}\text { Population } \\
\text { density }\end{array}$ & $\begin{array}{l}\text { The number of individuals in an area (square meter) } \\
\text { of each borough }\end{array}$ \\
\hline Subway & $\begin{array}{l}\text { Distance }(\mathrm{km}) \text { between the center of each apartment } \\
\text { complex and the nearest subway station }\end{array}$ \\
\hline Shopping & $\begin{array}{l}\text { The number of department store, major } \\
\text { supermarket, and traditional market within a 1-km } \\
\text { radius of the center of each apartment complex }\end{array}$ \\
\hline \multicolumn{2}{|r|}{ 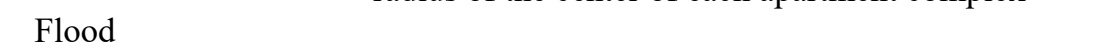 } \\
\hline Annual rainfall & Average rainfall $(\mathrm{mm})$ from May to October \\
\hline Rainfall intensity & $\begin{array}{l}\text { Average of the amount of rainfall }(\mathrm{mm}) \text { per rainy } \\
\text { days from May to October }\end{array}$ \\
\hline Impermeable & $\begin{array}{l}\text { The ratio }(\%) \text { between impermeable surface and } \\
\text { total area of each borough }\end{array}$ \\
\hline Sewer & The ratio $(\%)$ of sewer dredging of each borough \\
\hline
\end{tabular}

\subsection{Model}

This study focused its analysis on describing housing prices and flood-related variables using the double-log function because it is considered the logical form reflecting decreasing marginal utility between housing prices and housing characteristics. Morancho [6] explained that the double-log function allows us to measure the impact that changes in explanatory variables cause in the dependent variable in relative terms. The estimated coefficient shows price elasticity for a 
given independent variable. In the double-log function, all variables except for dummy, categorical, and count variables are transferred from their own values to logarithmic values. The double-log function can be represented as follows.

$$
\log P=a_{0}+a_{1} \log X_{1}+a_{2} \log X_{2}+\ldots+a_{k} \log X_{k}
$$

Table 2: Descriptive statistics of variables.

\begin{tabular}{|c|c|c|c|c|c|}
\hline Variables & Mean & $\begin{array}{l}\text { Standard } \\
\text { deviation }\end{array}$ & Range & Min & Max \\
\hline \multicolumn{6}{|l|}{ Dependent } \\
\hline Price & 605.86 & 254.5 & $1,661.91$ & 240.51 & $1,902.42$ \\
\hline \multicolumn{6}{|l|}{ Independent } \\
\hline \multicolumn{6}{|l|}{ Structural } \\
\hline Floor & 10.36 & 6.55 & 49.00 & 1.00 & 50.00 \\
\hline Age & 13.13 & 5.74 & 39.00 & 1.00 & 40.00 \\
\hline Floor ratio & 285.76 & 96.04 & 972.76 & 24.00 & 996.76 \\
\hline Building & 22.66 & 9.65 & 103.98 & 9.18 & 113.16 \\
\hline Building & 15.00 & 13.42 & 71.00 & 1.00 & 72.00 \\
\hline Parking & 1.21 & 0.63 & 11.59 & 0.28 & 11.87 \\
\hline Heating & 0.19 & 0.39 & 1.00 & 0.00 & 1.00 \\
\hline Brand & 0.15 & 0.35 & 1.00 & 0.00 & 1.00 \\
\hline \multicolumn{6}{|l|}{ Locational } \\
\hline Gangnam & 0.12 & 0.325 & 1.00 & 0.00 & 1.00 \\
\hline Fiscal & 42.72 & 15.65 & 53.60 & 22.30 & 75.90 \\
\hline $\begin{array}{l}\text { Population } \\
\text { density }\end{array}$ & $18,354.64$ & $4,530.37$ & $19,053.00$ & $9,501.00$ & $28,554.00$ \\
\hline Subway & 0.58 & 0.42 & 3.44 & 0.04 & 3.48 \\
\hline Shopping & 3.31 & 2.55 & 15.00 & 0.00 & 15.00 \\
\hline \multicolumn{6}{|l|}{ Flood } \\
\hline $\begin{array}{l}\text { Annual } \\
\text { rainfall }\end{array}$ & 45.59 & 3.12 & 11.95 & 38.86 & 50.81 \\
\hline $\begin{array}{l}\text { Rainfall } \\
\text { intensity }\end{array}$ & 23.71 & 1.15 & 4.32 & 21.3 & 25.62 \\
\hline Impermeable & 60.26 & 11.97 & 43.49 & 40.93 & 84.42 \\
\hline Sewer & 18.38 & 14.61 & 68.3 & 2.4 & 70.7 \\
\hline
\end{tabular}

The result of descriptive statistics is shown in Table 2. There were few econometric concerns before hedonic price analysis. The matter of autocorrelation was considered at first. By comparing between the value of Durbin-Watson statistics and that of the Durbin-Watson table, autocorrelation was tested. The Durbin-Watson statistics which was 1.850 showed there was no evidence of autocorrelation between residuals. As a next step, heteroscedasticity was checked through Glejser Test by regressing the absolute values of the residuals obtained 
from least-squares regression as explained by Glejser [5]. The values of significance in Glejser Test were greater than 0.05 , which reveals that there was no heteroscedasticity.

\section{Results}

The result of hedonic price analysis with double-log function using IBM SPSS Statistics (version 23) is shown in Table 3.

Table 3: Estimation results of the hedonic pricing model.

\begin{tabular}{lccccc}
\hline \multicolumn{1}{c}{ Variables } & Coefficient & Standard error & Beta & $\mathrm{t}^{\mathrm{a}}$ & VIF \\
\hline Constant & 9.715 & 0.655 & & $14.840^{* * *}$ & \\
Floor & 0.032 & 0.005 & 0.075 & $6.349^{* * *}$ & 1.104 \\
Age & -0.089 & 0.009 & -0.138 & $-9.981^{* * *}$ & 1.520 \\
Floor ratio & -0.050 & 0.018 & -0.040 & $-2.744^{*}$ & 1.731 \\
Building ratio & -0.133 & 0.018 & -0.116 & $-7.364 * * *$ & 1.995 \\
Building & 0.018 & 0.005 & 0.050 & $3.648^{* * *}$ & 1.508 \\
Parking & 0.068 & 0.013 & 0.070 & $5.142^{* * *}$ & 1.486 \\
Heating & 0.182 & 0.011 & 0.202 & $16.024 * * *$ & 1.265 \\
Brand & 0.100 & 0.013 & 0.100 & $7.938^{* * *}$ & 1.273 \\
Gangnam & 0.176 & 0.019 & 0.162 & $9.424 * * *$ & 2.370 \\
Fiscal & 0.502 & 0.024 & 0.488 & $20.764 * * *$ & 4.417 \\
Population density & 0.206 & 0.030 & 0.148 & $6.844 * * *$ & 3.734 \\
Subway & -0.099 & 0.007 & -0.179 & $-14.704 * * *$ & 1.188 \\
Shopping & 0.045 & 0.006 & 0.093 & $7.597 * * *$ & 1.192 \\
Annual rainfall & -0.603 & 0.082 & -0.118 & $-7.340^{* * *}$ & 2.074 \\
Rainfall intensity & -1.025 & 0.119 & -0.136 & $-8.618^{* * *}$ & 1.979 \\
Impermeable & -0.288 & 0.036 & -0.167 & $-7.897 * * *$ & 3.582 \\
Sewer & 0.033 & 0.008 & 0.061 & $3.982^{* * *}$ & 1.873 \\
\hline
\end{tabular}

a $*$ Significant at the 0.10 level, two-tailed test

**Significant at the 0.05 level, two-tailed test

***Significant at the 0.01 level, two-tailed test

As represented in Table 3, all selected variables were turned out to be statistically significant. The value of R-squared was 0.690 , and the value of adjusted R-squared was 0.687 . To assess multicollinearity, the variance inflation factor (VIF) was also examined. The values of VIF for all variables were below 10 , indicating there was no multicollinearity.

This result shows that housing prices decrease as the annual rainfall and rainfall intensity increase. And in infrastructure for flood protection, there is negative relationship between changes in impermeable surface ratio and those in housing prices. Changes in sewer dredging ratio and those in housing prices, On the contrary, have positive relationship. To look at the values of coefficient for identifying the magnitude of impact of these four variables (annual rainfall, 
rainfall intensity, impermeable surface ratio and sewer dredging ratio) on housing prices, as these variables grow by $1 \%$, housing prices decrease by $0.603 \%, 1.025 \%$, $0.288 \%$, and increase $0.033 \%$, respectively.

\section{Implications and conclusion}

All selected variables as flood characteristics were identified as factors affecting housing prices at statistically significant. It shows the physical characteristic of rainfall and infrastructure for flood protection form part of housing attributes on which housing buyers have additional willingness-to-pay (WTP). Housing buyers' WTP for $1 \%$ reduction in annual rainfall is 36,533 won $(605.86 * 0.00603)$ per square meter (exclusive use area) while housing buyers' WTP for $1 \%$ reduction in rainfall intensity is 62,101 won $(605.86 * 0.01025)$ per square meter. Housing buyers' WTP for $1 \%$ reduction in impermeable surface ratio is 17,449 won $(605.86 * 0.00288)$ per square meter while housing buyers' WTP for $1 \%$ increase in sewer dredging ratio is 1,999 won $(605.86 * 0.00033)$ per square meter.

Seoul established plans to diminish flood risks for areas prone to flooding in September, 2014. For example, mid- and long-term plan, such as improvement of sewer pipes and expansion of rainwater management systems, was established for Gwanghwamun area where serious flood damage occurred in 2010. In this context, this study which was for apartments in 25 boroughs of Seoul can be utilized to assess the impact of rainfall and flood risks in each borough.

As a very first study examining relationship between flood characteristics and housing prices, this study has significance for showing possibility that relationship between climate change and housing prices could be identified.

\section{References}

[1] IPCC., Climate Change 2014: Impacts, Adaptation, and Vulnerability. Part A: Global and Sectoral Aspects. Contribution of Working Group II to the Fifth Assessment Report of the Intergovernmental Panel on Climate Change, Cambridge University Press: Cambridge, United Kingdom, and New York, NY, pp. 535-612, 2014.

[2] Ahern, J., From fail-safe to safe-to-fail: Sustainability and resilience in the new urban world. Landscape and Urban Planning, 100(4), pp. 341-343, 2011.

[3] Can, A., Specification and estimation of hedonic housing price models. Regional science and urban economics, 22(3), pp. 453-474, 1992.

[4] Englin, J., Estimating the amenity value of rainfall. The Annals of Regional Science, 30(3), pp. 273-283, 1996.

[5] Glejser, H., A new test for heteroskedasticity. Journal of the American Statistical Association, 64(325), pp. 316-323, 1969.

[6] Morancho, A. B., A hedonic valuation of urban green areas. Landscape and urban planning, 66(1), pp. 35-41, 2003.

[7] Rehdanz, K., Hedonic pricing of climate change impacts to households in Great Britain. Climatic Change, 74(4), pp. 413-434, 2006. 
[8] Rosen, S., Hedonic prices and implicit markets: product differentiation in pure competition. Journal of political economy, 82(1), pp. 34-55, 1974.

[9] Wheater, H., \& Evans, E. (2009). Land use, water management and future flood risk. Land Use Policy, 26, S251-S264. 